\title{
Socio-cultural lock-ins and the difficulty of sustainability transition in fertilization - Response to Struckman
}

\author{
Suvi Huttunen \\ Department of Social Sciences and Philosophy, University of Jyväskylä, Finland \& \\ Environmental Policy Center, Finnish Environment Institute SYKE, Finland \\ suvi.m.huttunen@jyu.fi
}

\begin{abstract}
This commentary discusses the socio-cultural context of farming and proposes ways to break related lock-ins in the context of sustainability transition research. To be able to change farming practices and design policies to promote the changes, it is essential to understand what actually needs to change. Do we need to change the ways farmers think, the ways that food markets operate, the requirements of plant varieties or the requirements related to protecting water quality? In a complex situation the needed change emerges from the intertwinement of many different issues, which simultaneously work to create the locked-in situation. A focus on people and their practices provides a good starting point for understanding the intertwinement, and working in just ways to break the lock-ins.
\end{abstract}

Keywords: good farmer, agri-environmental policies, sustainability transition, practice change

I read with interest Luke Struckman's article on technological and institutional lock-in in nitrogen fertilizer use in North America. As a social scientist working with the question of changing farming practices in the context of agri-environmental policies, the article resonated well with my perceptions on fertilization practices and the barriers that prevent their change. Yet, it raised two points that merit further reflection. The first point relates to the importance of people and their socio-cultural contexts in change processes and the other calls for action to break the lock-ins in the context of sustainability transition research.

\section{Socio-cultural farming}

Struckman raises several important barriers that inhibit the change towards less intensive nitrogen fertilization. These include crop varieties, tillage practices, financial arrangements, marketing arrangements and ineffective water quality laws. In the context of tillage practices, he briefly raises cultural values as an explanation to the persistence of conventional practices. Cultural values and social norms represent a research area, which has gained increasing importance in relation to farming practices and their change (Burton 2004; Burton \& Paragahawewa 2011; Huttunen \& Peltomaa 2016). Broadly understood, these can be seen as part of institutional factors as suggested by Struckman, but they can also be examined from a more individual, identity related or practice-oriented perspectives (Stuart et al. 2014; Wheeler et al. 2018; Huttunen \& Oosterveer 2017). In the context of fertilization, cultural values and norms are not related to just tillage, rather they 
are interwoven with all farming practices, including fertilization itself.

From the identity related perspective, the cultural context of farming has been approached using the concept of "good farming" (Burton 2004). It refers broadly to the ways farming community understands a proper farmer to conduct agricultural production and manage his/her farm. The conceptualization derives mainly from Pierre Bourdieu's work on social and cultural capital. Farmers with appropriate cultural capital possess the skills, knowledge and objects, which make them desirable partners in social networks of the farming community. Good farming in North America and Europe is understood largely in productivist terms, which means that the core goal in farming is to produce efficiently large amounts of good quality food. The related cultural capital and thus the identity of good farmer is demonstrated to peer farmers via cultural symbols such as tidy fields, efficient machinery, large farm, high yields and tidy fields. Many environmentally friendly farming practices have been identified to conflict with core symbols related to good farming, especially those regarding tidy and fertile fields, which implies issues such as no weeds, large grains and includes conventional tillage. Hence, the adoption of reduced tillage, crop rotation with green manure, or lower fertilization levels, mean loss of cultural capital and the inability to demonstrate good farming identity (Burton \& Paragahawewa 2011). This has been used to explain the negative attitudes that conventional farmers may have in relation to organic farming, or the adoption of voluntary agri-environmental schemes. It can also be seen to work against reduced fertilization in North America.

The charm in good farming, as in any cultural understanding, is that it can also change. Farmer identities are heterogenous, not all farmers share the productivist ideals and this heterogeneity enables a slow change in the symbols of good farming (Sutherland \& Darnhofer 2012; Huttunen \& Peltomaa 2016; Wheeler et al. 2018). In the context of agri-environmental policies, it has been observed that the good farming ideals can also contribute to the accommodation and development of farming practices promoted by the policies (Huttunen \& Peltomaa 2016). In Finland, this has been clear in relation to zero or reduced tillage practices, which farmers saw as cost-effective and hence, sensible ways of producing yields with less inputs. Simultaneously practicing zero tillage and the way it makes fields appear was not considered as bad farming because it had become so common and people were used to it (Huttunen \& Peltomaa 2016). Similar cultural changes are occurring in relation to organic farming (Sutherland \& Darhofer 2012). In England and Wales, for some farmers, various environmentally beneficial farming practices have become a core part of good farming (Wheeler et al. 2018). Thus, it is clear that with time agri-environmental policies encouraging farmers to adopt new practices can also change the socio-cultural context of farming and function as breaking lock-ins.

In the context of the changing cultural understandings of good farming, it is important to note that the differences between farmers can be considerable even within a single country (Huttunen 2019). Farmers have different purposes for their farming activities, they have different perceptions in relation to the environment and the impacts of agricultural production. Farmers also have different kinds of constraints and 
enablers arising from the production line, location of the farm and family relations. In Finland, this means that some farmers practice highly intensive productivst farming, while some optimize carefully the utilized inputs vs. outputs in farming. Some famers even simplify their farming practices to the extent of not fertilizing nor producing anything for sale, rather, they focus on the subsidies available from nature management (Huttunen 2019). Also in the US, some farmers have been observed to optimize the fertilization rate in relation to the price of corn and fertilizers, while some are more wary of potential yield losses (Stuart et al. 2014). These kinds of differences mean that too simplistic accounts of the socio-cultural lock-ins risk to suggest poor and unjust policy solutions for solving the problems.

\section{Sustainability transition in fertilization}

What should then be done to break the socio-cultural as well as technical and institutional lock-ins? Transition to more sustainable socio-technical systems has gained wide interest in many societal domains, including also agriculture and food systems (Köhler et al. 2019; Bilali 2020). These studies point important ways towards institutional change starting from niche-innovations, new practices of the incumbent actors and facilitation by wider societal changes (Geels 2019). Dynamics and interlinkages between different parts of the system can be taken into account, and the ways technological solutions, markets, policy, science and culture constitute a locked-in stable regime can be understood. The socio-technical transition approach could provide a useful avenue also for the examination of the fertilization system in North America. Especially, since agro-food systems have not been extensively studied from this perspective (Hinrichs 2014; Bilali 2020). From the farming culture point of view, transition studies focusing on social practices and their change present a particularly useful direction in examining the potential for change in farming practices.

Practice theory is a means to better include farming culture and the diversity of farmers to socio-technical transition studies. It enables the examination of farming practices, such as fertilization, as the main focus of analysis. From a practice theoretical perspective, farming practices are constructed from three elements: 1) materials, such as fields, fertilizers and machines; 2) skills needed to perform the practice and 3) meanings related to the practice such as high yield or ease of application (Shove et al. 2012; Huttunen \& Oosterveer 2017). Thus, practices involve not only the meaning related issues, such as good farming identity. Instead, the practice perspective also accounts the ways fertilization, and farming practices in general, are influenced by multiple issues, which expand beyond farmer identities and function to construct them. This includes also issues that Struckman pointed out, such as financial arrangements and the needs of crop varieties, or seed farmers' contracts and the availability of tools related to precision agriculture as suggested in the US context by Stuart et al. (2014). These material element related issues can make it impossible to reduce fertilization rate. Also, poor skills related to new ways of farming can present a barrier for practice change. However, the point in practice approach is not to point out various 
barriers, but rather show their co-evolution, interdependence, and the ways the different elements of practices shape one-another and become routinized practices, which are hard to change.

We all have a general understanding on what fertilization practice is about. However, when we observe fertilization as it is practiced by different farmers, we can notice that there exists considerable variation in the ways fertilization is performed. In Finland, the differences in fertilization practices can be connected to wider purposes of farming, which determine the logics under which the different elements related to fertilization are composed (Huttunen \& Oosterveer 2017). Changes in fertilization could be related to wider changes in the ways the farm functions, such as production line or changes in farmer's personal life. Changes in material elements, such as policies or grain price trends could gradually build up practice change. Also changes in skills and meanings contribute. But in different farms the changes in the elements result in different kinds of fertilization practices, depending on the ways the elements are connected and influence each other.

For example, the introduction of a fertilization calculation method based on soil nutrient levels, could result in increased precision of fertilization in farms and reinforce the meaning of reducing leaching. However, for some farmers, it highlighted impoverishment of their soils and made the agri-environmental policies as seem unreasonable (Huttunen \& Oosterveer 2017). Or, the same conditions of rising fertilizer prices, stricter fertilization application limitations and low grain prices, made some farmers minimize their fertilizer application, while others developed a more encompassing fertilization system (Huttunen \& Oosterveer
2017). This makes the design of effective and acceptable policies difficult.

Farmers who practice fertilization are the meeting points of the different elements and they connect the different practices related to farming together. Thus, the focus on farmers' practices enables a grass-roots level examination of the diversity of the lock-ins and related different potentials for change. Together they create the systemic change.

\section{Conclusions}

Providing functioning solutions to complex environmental problems is not easy. When we want to change fertilization practices, it is relevant to clarify what we actually are changing. Do we need to change the ways farmers think, the ways that food markets operate, the requirements of plant varieties or the requirements related to protecting water quality? In a complex situation the needed change emerges from the intertwinement of many different issues, which simultaneously work to create the locked-in situation. In particular, there is a need to take into account the socio-cultural context alongside the diverse and intertwined lock-ins related to the technical, legal and financial aspects of the production system.

Via a focus on people and their practices, we are able to account for the diverse context and cultural understandings of farmers and identify seeds of change. This requires also the recognition of farmers' different needs and capabilities in relation to the desired change. The focus on farmers can also reveal that the most important routes for change lie in markets, supply chains or state policies, which intertwine with farming practices and provide a window to the wider 
system. Thus, increasing focus on people and their practices in transitions creates a new basis for facilitating more acceptable sustainability transition.

\section{Acknowledgements}

The work was supported by the Academy of Finland Strategic Research Council, grant 327369 (Just Food-project).

\section{References}

Bilali, H. E. (2020). Transition heuristics frameworks in research on agro-food sustainability transitions. Environment, Development and Sustainability 22, 1693-1728. DOI: https://doi. org/10.1007/s10668-018-0290-0

Burton, R. J. F. (2004). Seeing through the 'good farmer's' eyes: towards developing an understanding of the social symbolic value of 'productivist' behavior. Sociologia Ruralis 44:2, 195-216.

Burton, R. J. F. \& U. H. Paragahawewa (2011). Creating culturally sustainable agri-environmental schemes. Journal of Rural Studies 27:1, 95-104.

Geels, F. W. (2019). Socio-technical transition to sustainability: a review of criticisms and elaborations of the multi-level perspective. Current Opinion in Environmental Sustainability 39, 187-201.

Hinrichs, C.C. (2014). Transitions to sustainability: a change in thinking about food systems change? Agriculture and Human Values 31, 143-155.

Huttunen, S. (2019). Revisiting agricultural modernisation: Interconnected farming practices driving rural development at the farm level. Journal of Rural Studies 71, 36-45.

Huttunen, S. \& P. Oosterveer (2017). Transition to sustainable fertilization in agriculture, a practices approach. Sociologia Ruralis 57:2, 191-210.

Huttunen, S. \& J. Peltomaa (2016). Agri-environmental policies and 'good farming' in cultivation practices at Finnish farms. Journal of Rural Studies 44, 217-226.

Köhler, J., F. W. Geels, F. Kern, J. Markard, A. Wieczorek, F. Alkemade, F. Avelino, A. Bergek, F. Boons, L. Fünfschilling, D. Hess, G. Holtz, S. Hyysalo, K. Jenkins, P. Kivimaa, M. Martiskainen, A. McMeekin, M. S. Mühlemeier, B. Nykvist, E. Onsongo, B. Pel, R. Raven, H. Rohracher, B. Sandén, J. Schot, B. Sovacool, B. Turnheim, D.
Welch, \& P. Wells (2019). An agenda for sustainability transitions research: State of the art and future directions. Environmental Innovation and Societal Transitions 31: 1-32.

Shove, E., M. Panzar, \& M. Watson (2012). The dynamics of social practice. London: Sage Publications.

Sutherland, L. A., \& I. Darnhofer (2012). Of organic farmers and 'good farmers': Changing habitus in rural England. Journal of Rural Studies 28: 232-240.

Stuart, D., R. L. Schewe \& M. McDermott (2014). Reducing nitrogen fertilizer application as a climate change mitigation strategy: understanding farmer decision-making and potential barriers to change in the US. Land Use Policy 36, 210-218.

Wheeler, R., M. Lobley, M. Winter \& C. Morris (2018). "The good guys are doing it anyway": The accommodation of environmental concern among English and Welsh farmers. Environment and Planning E: Nature and Space 1:4, 664-687. 